\title{
Features of the FEC functioning modeling for solving the selecting critical facilities problem
}

\author{
Natalia Beresneva ${ }^{1}$, Natalia Pyatkova*1 \\ ${ }^{1}$ Melentiev Energy Systems Institute, 130 Lermontov str., Irkutsk, Russia
}

\begin{abstract}
The paper presents the system of models for the fuel and energy complex functioning used to determine the critically important facilities, built on the basis of the fuel and energy complex territorial production model of the . A formalized representation of the model is given, a three-stage scheme for working with it is described. For the selection of the fuel and energy complex critically important facilities, the most important and accompanying model indicators are highlighted, an integral indicator of the industry elements criticality is proposed. The results of testing the developed models are presented (illustrative example).
\end{abstract}

\section{Introduction}

The task of searching the fuel and energy complex CF [1-2] has been actualized in the last few years and has become a logical continuation of the task of selecting critically important industry facilities [3-4], and it was aimed at confirming the criticality of industry facilities in the conditions of joint work of all industries and existing mechanisms providing consumers with the necessary energy resources. For the task of searching for the $\mathrm{CF}$ of the fuel and energy complex, a two-stage research scheme has been developed, at the first stage of which critical industry facilities are determined at the level of individual industries. At the second stage, within the framework of general energy research, their significance for the fuel and energy complex as a whole is confirmed. This research scheme correlates with a two-level model scheme, the lower level of which is represented by sectoral models, the upper one - by territorial production models of the fuel and energy complex [5]. Methodologically, the problem of determining the $\mathrm{CF}$ of the fuel and energy complex is formalized at the level of general energy studies, and has the following brief formulation.

It is necessary, within the framework of scenario studies of the fuel and energy complex functioning on the basis of fuel and energy resources deficits, which are formed in various categories of consumers, to assess the criticality of industrial facilities for individual territories or their groups, provided that: - the list of industry objects is represented by critically important industry objects found on the industry model; - design scenarios - situations of specified industry facilities inoperability (shutdowns of individual facilities or their groups are specified); - assessment of the criticality of each industrial facility for the fuel and energy complex as a whole - a generalized assessment of the relative deficits for all resources for all categories of consumers; - the choice of the fuel and energy complex CEP is carried out taking into account the degree of activation of the structural redundancy possibilities in the industries.

This formulation of the problem presupposes the maximum elaboration of the structural redundancy mechanisms in the fuel and energy complex functioning model, requires an adequate representation of the analyzed industry objects in the territorial-production structure of the fuel and energy complex. This leads to the need to develop new versions of the fuel and energy complex functioning model, focused on a more detailed study of the analyzed industry structures. An example of the development and testing of such a model for the case of choosing critical gas facilities for the fuel and energy complex is discussed in this article.

\section{Scheme and algorithm for developing a model for solving the problem of choosing a fuel and energy complex critical facilities}

To solve the problem of searching for the fuel and energy complex critical facilities, a new version of the fuel and energy complex functioning model has been developed. The development of this version was carried out on the basis of two different-level models: the general energy territorial production model of the fuel and energy complex and the sectoral model of the UGSS of Russia. The choice of these models was justified by the formulation of the problem to be solved - the problem of determining the most critical for the fuel and energy complex objects of the gas industry in the conditions of joint functioning of the energy industries.

* Corresponding author: nata@isem.irk.ru 
The fuel and energy complex model is used to assess the criticality of gas facilities identified in the framework of certain model studies of the UGSS of Russia.

The development of the fuel and energy complex model was carried out in accordance with the model modification scheme presented in [6]. At the same time, the following stand out: 1) the structural component of basic models (models on the basis of which the modification is carried out); 2) the informational component of these models; 3) tasks to be solved.

The technology of the model modernization for solving the problem of choosing the fuel and energy complex CF is shown in (Fig. 1).

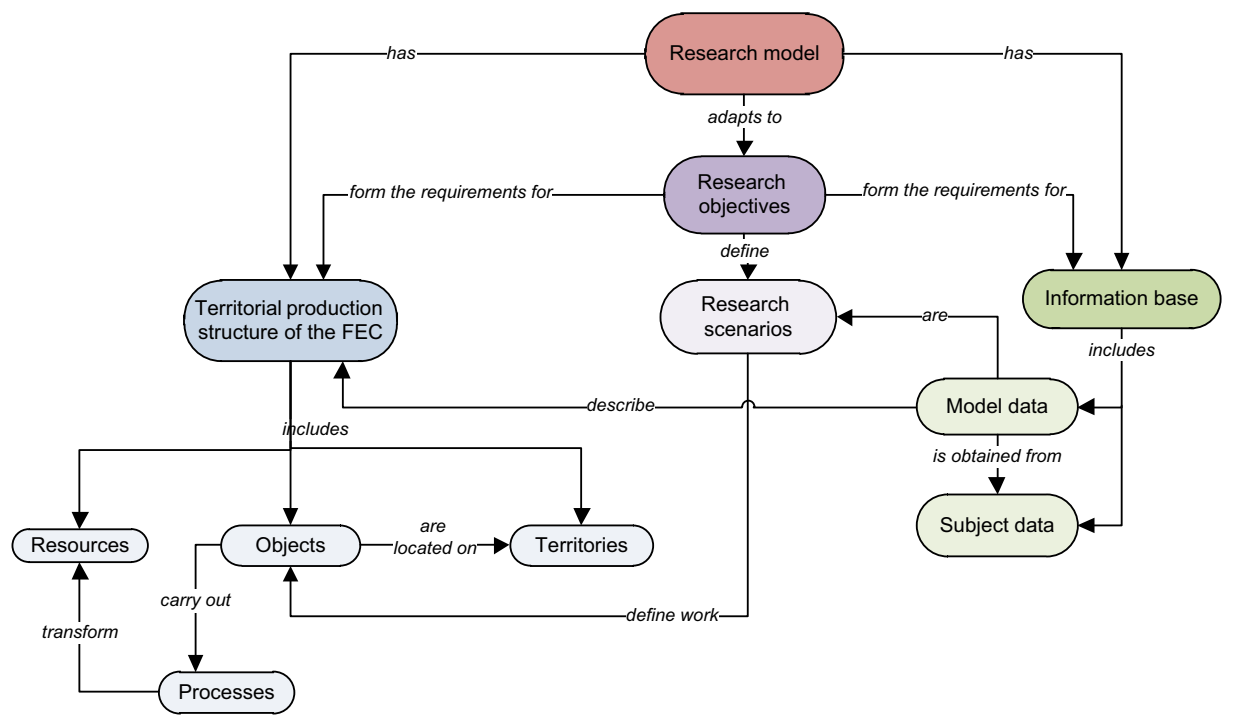

Fig. 1 The technology of the model modernization for solving the problem of choosing the fuel and energy complex CF.

The last component in this technology is of the highest priority, since it is it that determines the territorial-production structure of the modeled object (industry or fuel and energy complex), sets the requirements for the model itself. Also, the tasks to be solved affect the composition and level of information detail, the choice of data sources, forms a set of algorithms for verifying and converting these data into model ones. The model obtained in this case includes the characteristics of the basic models, it can acquire new characteristics that are not characteristic of the basic models, which are necessary for solving the tasks.

The use of this technology for modifying models to solve the problem of searching for the fuel and energy complex:

- does not conflict the two-stage scheme for identifying industry facilities that are critical for the fuel and energy complex, at the first stage of which critical industry facilities are identified, on the second proves their criticality for the fuel and energy complex as a whole; - allows you to obtain a model for the study of the fuel and energy complex for the second stage of the CA determining with the required degree of industry objects detail;

- supports the ability to model the mechanisms of reservation and interchangeability of resources in the the fuel and energy complex model; - allows you to take into account the features of the existing information component, its composition and consistency degree.
In the case of identifying gas industry facilities that are critical for the fuel and energy complex, the use of this technology made it possible to achieve the identity of the country's UGSS calculation scheme in the models of both levels, and made it possible to directly form scenarios of the analyzed industrial facilities inoperability. The joint use of sectoral and general energy information with varying degrees of detail was achieved without additional preparation of data on gas facilities. The most important result of the fuel and energy complex model the modification was the adjustment of the electric and heat power facilities operating modes. The ratio of the basic and resulting research models on key aspects of the industries functioning presented in Table 1.

The features of the fuel and energy complex functioning model new version for identifying gas industry facilities that are critical for the fuel and energy complex are as follows:

- integration of the of the of Russia's UGSS calculation scheme from the sectoral model into the general energy model;

- modeling of thermal power plants and boiler houses backup operation; - formation of a seasonal irregularity coefficients block, a block of specific cost and penalty coefficients. 
Table 1. Key characteristics of the used models

\begin{tabular}{|c|c|c|c|}
\hline & \multicolumn{2}{|c|}{ Basic models } & \multirow{2}{*}{$\begin{array}{l}\text { Fuel and energy complex model for } \\
\text { determining the fuel and energy complex }\end{array}$} \\
\hline & $\begin{array}{c}\text { Fuel and energy complex } \\
\text { model }\end{array}$ & UGSS model & \\
\hline $\begin{array}{l}\text { Time aspect of } \\
\text { technological } \\
\text { processes }\end{array}$ & Year, day & Day & Day \\
\hline Energy resources & $\begin{array}{l}\text { Gas, heating oil, coal } \\
\text { (coal, brown), other } \\
\text { types of fuel, heat, } \\
\text { electricity }\end{array}$ & Gas & $\begin{array}{l}\text { Gas, heating oil, diesel fuel ,coal (coal, } \\
\text { brown), other types of fuel, heat, electricity. }\end{array}$ \\
\hline $\begin{array}{l}\text { Features of the } \\
\text { presentation of } \\
\text { technological } \\
\text { processes of fuel } \\
\text { industries }\end{array}$ & $\begin{array}{l}\text { Aggregated by various } \\
\text { types of industry } \\
\text { facilities, by constituent } \\
\text { entities of the Russian } \\
\text { Federation }\end{array}$ & $\begin{array}{l}\text { Technological units of } \\
\text { the UGSS of Russia: } \\
\text { sources, UGS facilities, } \\
\text { compressor stations, } \\
\text { consumers (districts, } \\
\text { cities, largest state } \\
\text { district power plants), } \\
\text { gas pipelines }\end{array}$ & $\begin{array}{l}\text { Gas industry: } \\
\text { 1. In the zone of influence of the UGSS: } \\
\text { - sources, UGS facilities, compressor stations, } \\
\text { gas pipelines); } \\
\text { - groups of TPPs, groups of boiler houses, and } \\
\text { other consumers assigned to the subjects; } \\
\text { - importing countries. } \\
\text { 2. Outside the zone of influence of the UGSS, } \\
\text { subjects-sources, subjects-consumers } \\
\text { For other industries: sources, storage facilities, } \\
\text { aggregated railway network, mandatory needs } \\
\text { of regions, importing countries, exporting } \\
\text { countries. }\end{array}$ \\
\hline $\begin{array}{l}\text { Features of the } \\
\text { presentation of } \\
\text { technological } \\
\text { processes in } \\
\text { electrical and heat } \\
\text { power } \\
\text { engineering }\end{array}$ & $\begin{array}{l}\text { NPP, HPP, TPP; Wind } \\
\text { power plants, solar } \\
\text { power plants, geo power } \\
\text { plants, pumped storage } \\
\text { power plants, boiler } \\
\text { houses assigned to the } \\
\text { constituent entities of the } \\
\text { Russian Federation. } \\
\text { Transport infrastructure } \\
\text { is an aggregated power } \\
\text { transmission line } \\
\text { network. Exporting } \\
\text { countries, importing } \\
\text { countries of electricity.. }\end{array}$ & & $\begin{array}{l}\text { Aggregated by stations (NPP, HPP, TPP, } \\
\text { small IES, WPP, SES, GeoPP, PSP) and boiler } \\
\text { houses assigned to the constituent entities of } \\
\text { the Russian Federation. Transport } \\
\text { infrastructure is an aggregated power } \\
\text { transmission line network. Exporting } \\
\text { countries, importing countries of electricity . }\end{array}$ \\
\hline $\begin{array}{l}\text { Structural } \\
\text { redundancy }\end{array}$ & $\begin{array}{l}\text { Fuel reserves in the } \\
\text { constituent entities at the } \\
\text { beginning of the billing } \\
\text { period, } \\
\text { interchangeability of gas } \\
\text { and fuel oil at TPPs and } \\
\text { in boiler houses in their } \\
\text { normal mode of } \\
\text { operation }\end{array}$ & $\begin{array}{llr}\text { Maximum } & \text { daily } & \text { gas } \\
\text { withdrawal from } & \text { UGS } \\
\text { facilities } & & \end{array}$ & $\begin{array}{l}\text { In the fuel industries (except for gas), resource } \\
\text { reserves in the regions at the beginning of the } \\
\text { billing period. The gas industry has the } \\
\text { maximum daily gas withdrawal from UGS } \\
\text { facilities. In the electric and heat power } \\
\text { industry, the task of additional generating } \\
\text { capabilities of TPPs and boiler houses, support } \\
\text { of the interchangeability of gas and fuel oil } \\
\text { during the operation of these facilities }\end{array}$ \\
\hline
\end{tabular}

The integration of the Russian UGSS calculation scheme into the fuel and energy complex functioning model was carried out with the following assumptions: 1. In the UGSS scheme for territories from the UGSS influence zone, it is allowed to replace gas consumers with facilities from the fuel and energy complex model. Thus, the categorization of consumers adopted in the fuel and energy complex model is preserved, the interaction of the gas industry, electricity and heat power engineering is observed. 2. For the territories in the UGSS influence zone, the composition of sources, compressor stations, UGS facilities, gas pipelines specified in the industry model remains unchanged. The most important condition is compliance with the correspodence of gas production volumes in both models for these territories. 3. For territories not included in the UGSS influence zone, the data of the fuel and energy complex model for gas production and consumption are updated. If there is a transport infrastructure outside the UGSS (for example, in the Far East), the fuel and energy complex model additionally includes the corresponding enlarged transport schemes. 
Calculations on the fuel and energy complex model with such a detailed diagram of the Russian gas industry showed the presence of locked gas sources in the case of linking the latter to consumers that are not schematically associated with the territories of their location. Another consequence of the different presentations of consumers in different-level models is the need to verify the characteristics of gas pipelines. In general, the results of the fuel and energy complex functioning obtained on the basis of the transformed sectoral scheme of the UGSS were recognized as adequate from the standpoint of the interrelated work of the industries.

Modeling of the operation of TPPs and boiler houses reserve mode was carried out taking into account the additional supply of electricity and heat in the event of increased demand for these resources during the heating period. For this, information from two sources was used and agreed upon:

- from statistical reports on the production characteristics of TPPs and boiler houses in the reporting year;

from the information and analytical report "Heat and district heating in Russia" of the Federal State Budgetary Institution "REA", the monthly reporting of the Unified Energy System system operator.

The need to coordinate these sources was founded: the incorrectness of the production capabilities of TPPs and boiler houses data encountered in statistical reporting;

- narrow specialization of used information and analytical reporting.

The reserve capabilities of heat and electricity supply from TPPs and boiler houses were determined according to the following scheme: - determination of peak daily needs for electricity and heat from the used information and analytical reporting; - determination of reserve possibilities for the supply of electricity and heat from TPPs and boiler houses for the given production capabilities of these facilities; - checking the coverage of peak daily needs for electricity and heat, taking into account the TPPs and boiler houses reserve capabilities; - adjustment of the TPPs and boiler houses specified reserve capabilities, taking into account the structure of electricity and heat supply, the structure of fuel consumption, and the specifics of providing the territories with boiler and furnace fuel.

The decrease in electricity generation by hydroelectric power plants in winter was also taken into account. The modification resulted in a version of the fuel and energy complex functioning model with an industry structure, conceptually presented in Fig. 2.

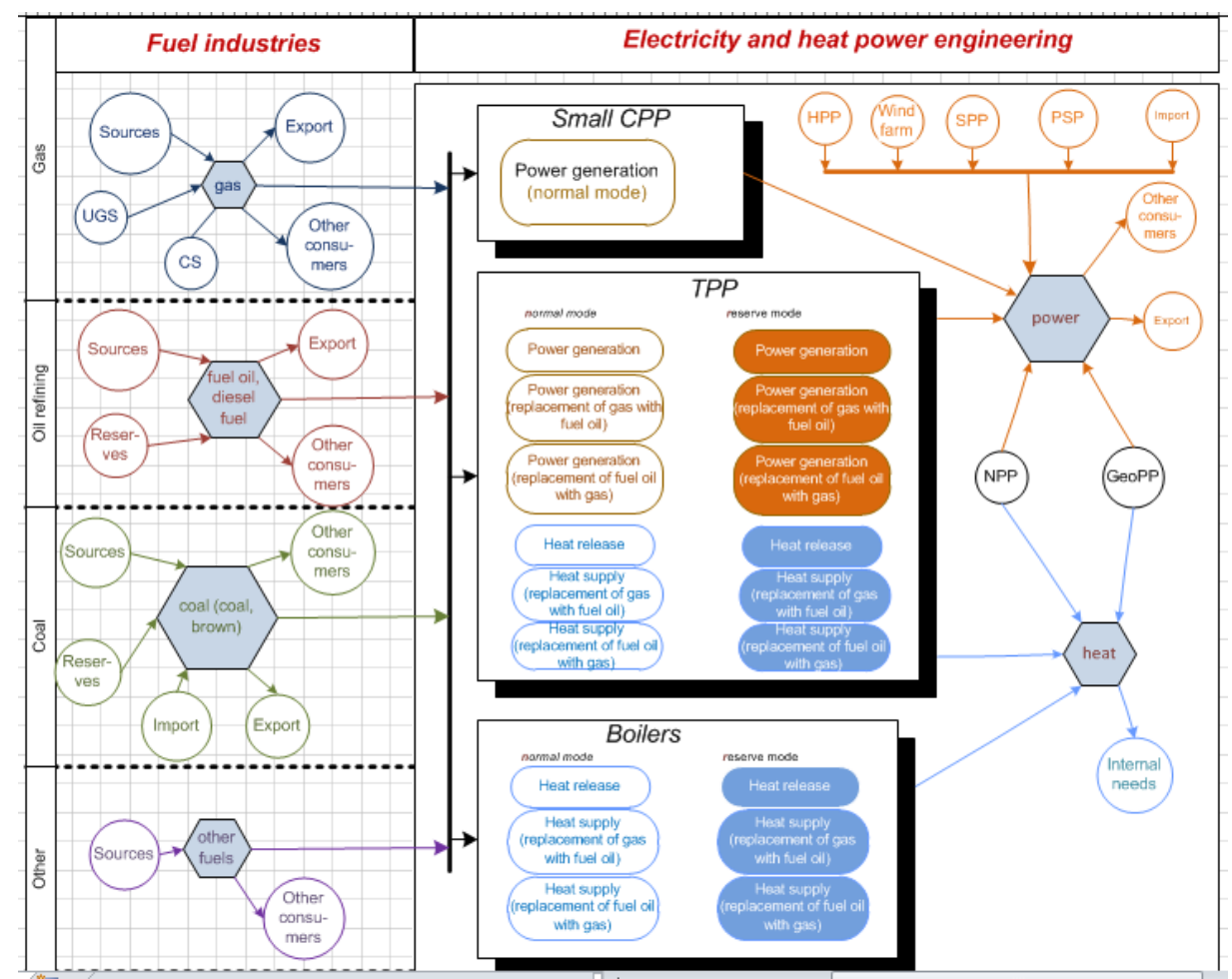

Figure: 2.Technological structure of the fuel and energy complex functioning model for identifying critical gas facilities for the fuel and energy complex

When choosing critical elements of the fuel and energy complex on the basis of industry-specific ones, three types of daily variants of the model daily variants are formed: the average daily balanced version, the version of the energy facilities maximum load, the versions for shutting down industry critical elements at the facilities maximum load. 


\section{Analysis of the results of experimental calculations using a modified model}

In the new version, the model is represented by 80 subjects of the federation, aggregated by 8 federal districts. The technological scheme of the model is shown above in Fig. 2.

Also, the new version of the model uses the UGSS design scheme, which takes into account all the main features of the Russian UGSS functioning and contains:

- 378 nodes, including: 28 gas sources; 64 gas consumers (constituent entities of the Russian Federation); 24 underground gas storage facilities; 266 nodal compressor stations;
- 486 arcs representing gas trunklines and branches to gas distribution networks.

Using the developed model, a number of experimental calculations were carried out, in which the influence of critical elements shutdown at the gas industry (61 elements) on the functioning of the fuel and energy complex as a whole was analyzed as design conditions. The result of the sequential shutdown of the selected objects of the gas industry was a decrease in the production of the energy resources considered in the model and, accordingly, a consumers shortage.

In the country as a whole, for each disconnected facility in the gas industry, the following situation has developed, Fig.3.

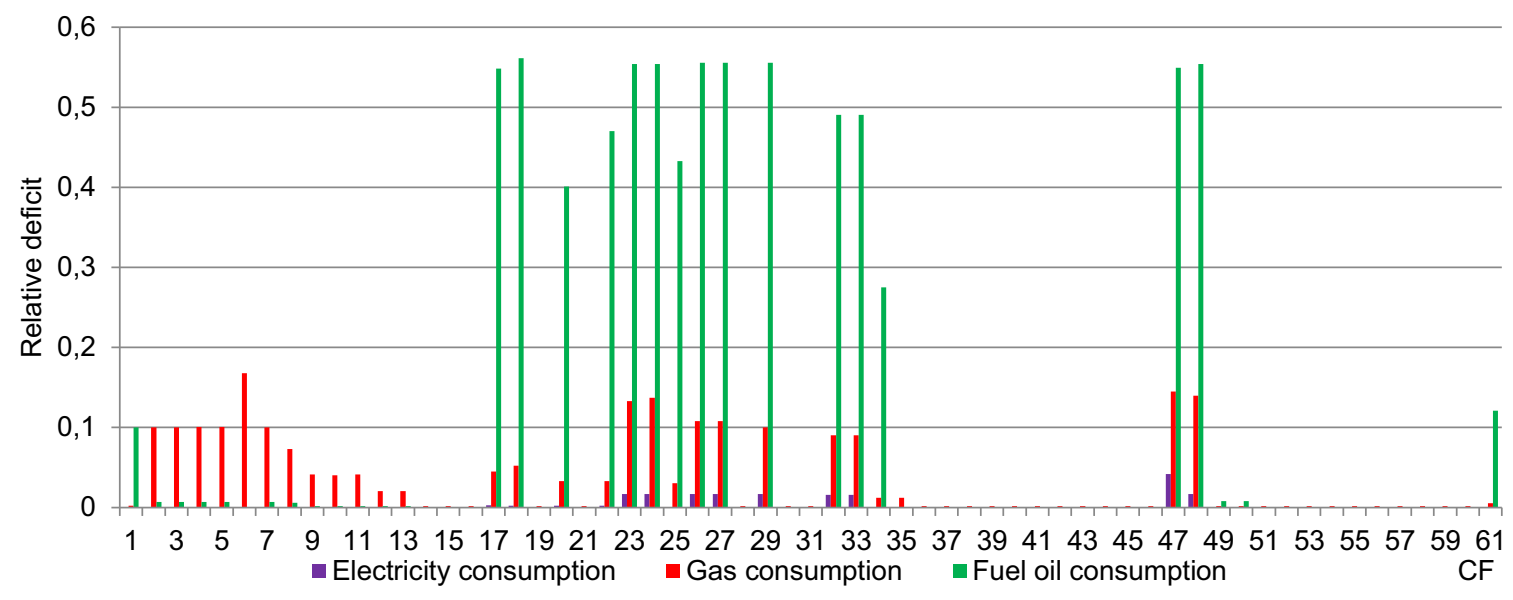

Figure: 3. Relative shortage of energy resources when critical elements of the gas system are turned off, share of units.

When determining the significance coefficients, potential critical elements were excluded, when the deficits of energy resources were less than $5 \%$ of the needs.

The analysis of the obtained results showed that the list of critical elements for the fuel and energy complex differs from the initial ranked set of critical elements of the gas industry When considering the mutually coordinated work of all industries, a systemic effect had a significant impact, firstly, by reducing the deficit among consumers from insufficient gas supply, and secondly, by changing the priority of critical facilities for the fuel and energy complex. As a result, from the initial list of 61 critical elements in the gas industry, 25 elements remained, the shutdown of which led to significant undersupply of energy resources (Fig. 4). At the same time, the significance indicator takes into account the reserves using, the amount of fuel diversification at power plants with a double fuel supply, which can reduce fuel shortages due to the shutdown of the analyzed elements at the gas industry.

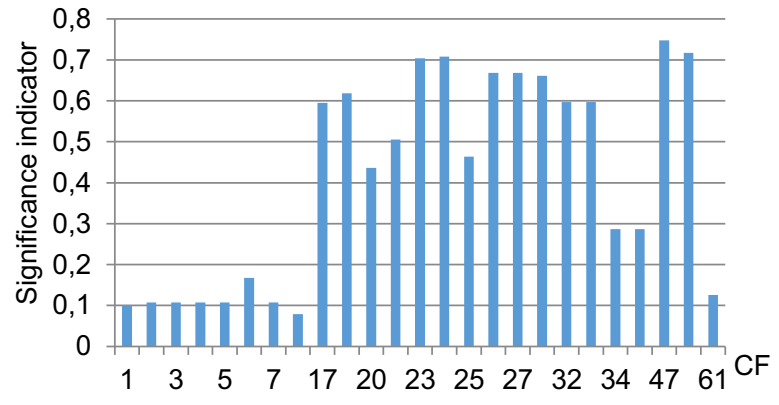

Figure: 4. Coefficients of critical elements significance at the gas system

For federal districts, the priority of critical elements at the gas industry in terms of their impact on energy supply to consumers differs from the ranking for the country as a whole. Below are the quantitative indicators of these values (Fig. 5). 


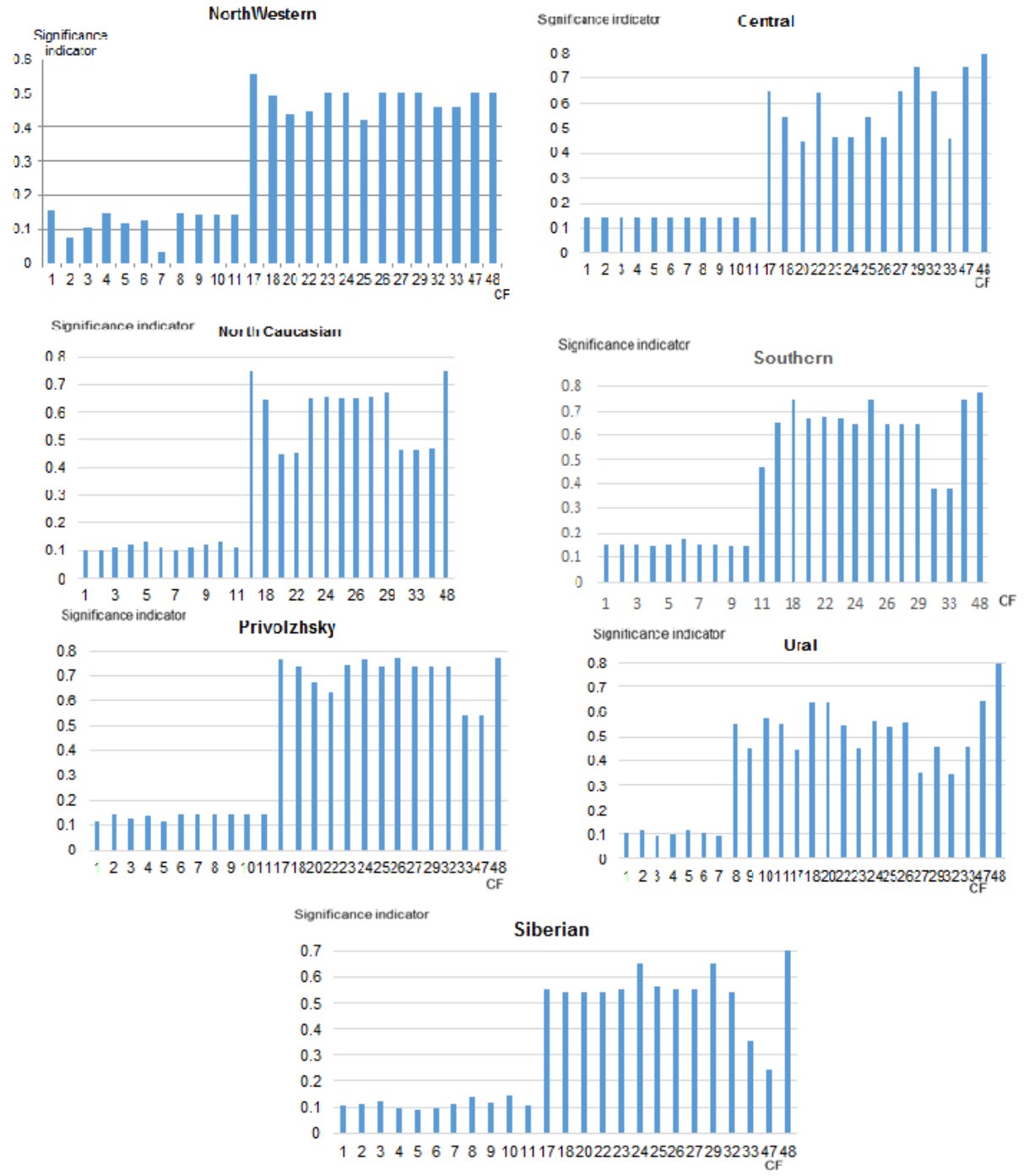

Figure: 5. Coefficients of critical elements significance at the gas system by federal districts

Three categories of critical elements were identified according to their impact on energy supply (according to the magnitude of the deficit resulting from the shutdown of critical elements at the gas industry): 1 category, which includes the elements causing a total relative deficit of over $70 \%, 2$ category from 30 to $70 \%, 3$ category - indicators below $30 \%$. The number of critical elements by these groups throughout the country (by federal districts) was distributed as follows (Table 1). A significant deficit was obtained in the territories, the fuel and energy balance of which is focused on the use of natural gas. These are the North Caucasian, Volga, Central and Southern districts, where the number of critical elements of the first category was 12-14 objects.

Table. 2.Classification of the gas industry critical elements according to the impact on the energy supply to consumers

\begin{tabular}{|l|c|c|c|}
\hline \multicolumn{1}{|c|}{ Federal District } & $\begin{array}{c}\text { category }(100- \\
70 \%)\end{array}$ & $\begin{array}{c}2 \text { category (69- } \\
30 \%)\end{array}$ & $\begin{array}{c}3 \text { category (29- } \\
0 \%)\end{array}$ \\
\hline Central & 14 & - & 11 \\
\hline Northwestern & 10 & 3 & 12 \\
\hline South & 12 & 11 & 11 \\
\hline North Caucasian & 14 & - & 11 \\
\hline Volga & 14 & - & 5 \\
\hline Ural & 6 & 14 & 11 \\
\hline Siberian & 7 & 7 & 2 \\
\hline
\end{tabular}




\section{Conclusion}

The paper presents the main features of the fuel and energy complex constructing models to identify critical industry objects. These features are related:

- taking into account the time aspect of technological processes in the fuel and energy sector, - with a presentation of technological processes in the fuel industries and especially in the electric and heat power system,

- with the allocation of structural redundancy funds to reduce the impact of emergency situations when industry systems critical elements are disconnected. A model of the fuel and energy complex functioning with a detailed representation of the Russia UGSS is considered. The results of experimental calculations to determine the the fuel and energy complex CF using the new version of the model are presented. The article presents the results of an analysis of the magnitude of relative deficits, the critical elements significance coefficients for the gas industry in the country and federal districts, taking into account the systemic effect of the mutually coordinated work of sectoral systems within a single fuel and energy complex.

This work was carried out with the financial support of the RFBR grant No. 20-08-00367

\section{Literature}

1. Beresneva N.M., Pyatkova N.I. Choosing of the FEC critical objects in model researches of energy security problems and its features / Rudenko International Conference "Methodological problems in reliability study of large energy systems" (RSES 2018), Vol.58. ID: $03004 . \quad 2018 . \quad$ DOI: 10.1051/e3sconf/20185803004

2. Pyatkova N.I., Berseneva N.M. Determination of critical elements of the fuel and energy complex from the standpoint of reliable power supply // Izvestiya RAN. Energy, 2020, No. 1, p. 72-81.

3. Senderov S.M, Vorobev S.V. Approaches to the identification of critical facilities and critical combinations of facilities in the gas industry in terms of its operability. Reliability Engineering \& System Safety, Volume 203, November 2020, 107046

4. Vorobiev S.V., Edelev A.V. Application of the method for determining critical elements in the networks of technical infrastructures for the search for critical objects of the gas transmission network of Russia // Energy Policy, 2018, No. 1, p. 45-51.

5. Beresneva N.M. Methodological issues of modifying economic and mathematical models in studies of energy security in Russia // Izvestiya RAN. Energy. \# 2. 2015. S. 30-41.

6. Systems research in energy: Retrospective of the scientific directions of SEI-ISEM. otv. ed. N.I. Shout. Novosibirsk: Nauka, 2010 .-- 686 p.

7. Ministry of Energy of the Russian Federation. Statistics. http://minenergo.gov.ru/activity/statistic 